các bệnh viện cùng hạng trên toàn quốc. 2015; Thông tư liên tịch số 37/2015/TTLT-BYT-BTC.

5. Chính Phủ. Quy định cơ chế tự chủ của đơn vị sự nghiệp công lập. 2015; Nghị định số 16/2015/ND-CP.

6. Chính Phủ. Về cơ chế hoạt động, cơ chế tài chính đối với các đớn vị sự nghiệp y tế công lập và giá dịch vụ KCB của các cơ sở KCB công lập. 2012; Nghi đinh số 85/2012/NĐ-CP

7. Dương Tuấn Đức. Nghiên cứu cơ cấu bênh tật và chi phí của người bệnh bảo hiểm y tế điều trị nội trú tại Hà Nội năm 2004. Luận văn thạc sỹ y tế công cộng. 2004.

\title{
ĐÁNH GIÁ KẾT QUẢ SỚM PHẪU THUÂT CẮT GẦN TOÀN Bộ DẠ DÀY VÉT HACH TRONG ĐIỀU TRI UNG THƯ DA DÀY Ở NGƯỜI CAO TUỔI
}

\author{
Phạm Thế Dương ${ }^{1}$, Kim Văn Vụ̂1,2, \\ Nguyễn Tiến Trung ${ }^{2}$, Phạm Trung Thông ${ }^{2}$, Nguyễn Hoàng Minh ${ }^{2}$
}

\section{TÓM TẮT}

Muc tiêu: Đánh giá kết quả sớm phẫu thuât cắt gân toàn bộ dạ dày vét hạch do ung thư ở người cao tuổi. Đối tượng và phương pháp: Nghiên cứu mô tả cắt ngang trên 111 bệnh nhân ung thư dạ dày trên 70 tuổi được phẫu thuất triệt căn cắt gần toàn bô da dày, vét hạch tại bệnh viện $K$ từ tháng 6/2018 đến tháng $6 / 2021$. Kết quả: Tỷ lê bênh nhân có bênh lý nền là 48,6\%. Vét hach D2 được tiến hành ở $67,6 \%$ bệnh nhân. Không có trường hợp nào tử vong sau mổ, tỷ lệ biến chứng chung của phẩu thuật là $11,7 \%$, trong đó thường gặp nhất là viêm phổi $(4,5 \%)$. Thời gian trung tiện: $3,10 \pm 0,65$ ngày. Thời gian cho ăn: $3,72 \pm 0,68$ ngày. Thời gian nằm viện: $10,74 \pm 3,37$ ngày. Có bệnh lý nền, vét hach D2 không làm tăng nguy cơ biến chứng và kéo dải thời gian nẳm viện so với nhóm bệnh nhân còn lại. Kết luận: Phẫu thuật triệt căn cắt gần toàn bô da dày, vét hạch do ung thư ở người cao tuổi có thể tiển hành an toàn. Vét hach D2 hay dưới D2 cần cân nhắc dựa trên đặc điểm từng người bênh.

Tư k hóa: Ung thư dạ dày, người cao tuổi, cắt gân toàn bộ dạ dày.

\section{SUMMARY}

INITIAL RESULTS OF SUBTOTAL

\section{GASTRECTOMY FOR GASTRIC CANCER} IN EDERLY PATIENTS

Purpose: To evaluate the feasibility and initial results of subtotal gastrectomy for gastric cancer in elderly patients. Patients and method: A cross sectional study on 111 elderly patients (aged 70 years or above) who underwent radical subtotal gastrectomy in the National cancer hospital from June 2018 to June 2021. Results: The rate of comorbidity was $48,6 \%$. D2 lymphadenectomy was performed in $67,6 \%$ patients. There was no operative mortality, morbidity occurred in 13 of 111 patients $(11,7 \%)$. Pneumonia

${ }^{1}$ Trường Đại học Y Hà Nội

${ }^{2}$ Bênh viên $K$

Chiu trách nhiệm chính: Phạm Thế Dương

Email: Theduongasdf@gmail.com

Ngày nhận bài: 8.7.2021

Ngày phản biên khoa học: 31.8.2021

Ngày duyệt bài: 9.9.2021 was the most common complication (4,5\%). The mean time to first passage of flatus: $3,10 \pm 0,65$ days. The mean time for beginning oral feeding was $3,72 \pm 0,68$ days. Hospital stay: $10,74 \pm 3,37$ days. Comorbidity and D2 lymph node dissection were not the risk factor for postoperative complications and prolonged hospital length of stay. Conclusion: Radical subtotal gastrectomy in ederly patients was safe and feasible. D2 or D1, D1+ lymph node dissection should be considered in invidual characteristics.

Key words: Gastric cancer, ederly patients, subtotal gastrectomy.

\section{I. ĐĂT VẤN ĐỀ}

Ung thư da dày là ung thư thường găp, đứng hàng thứ 5 về tỷ lệ mới mắc và thứ 4 về tỷ lệ tử vong do ung thư trên toàn thế giới. Ung thư da dày có tỷ lệ mắc tăng dân theo tuổi, độ tuổi thường gặp nhất từ 60 - 70. Hiện nay, phẫu thuật vẫn là phương pháp điều trị chính đối với các trường hợp ung thư dạ dày còn khả năng cắt bỏ. Đối tượng người cao tuổi thường có nhiêu bênh mạ tính kèm theo như các bệnh lý tim mạch, đái tháo đường, hô hấp, thần kinh,... phối hợp tình trạng sức khỏe suy yếu do bệnh lý ung thư, là yếu tố nguy cơ cao gây biến chứng trong và sau mổ. Tuy nhiên trong những năm gân đây, những tiến bô trong gây mê và hồi sức sau mố đã giúp giảm thiểu các biến chứng và do đó cải thiện đáng kể kết quả sớm sau phẫu thuật. Mục tiêu của nghiên cứu nhằm đánh giá tính khả thi và mức đô̂ an toàn của phẫu thuâtt triêt căn cắt gân toàn bộ dạ dày vét hạch ở người cao tuổi, qua đó xác định một số yếu tố liên quan tới biến chứng sau phẫu thuật và thời gian nằm viện.

\section{II. ĐỐI TƯỢNG VÀ PHƯƠNG PHÁP NGHIÊN CỨU \\ Đối tượng nghiên cứu. Các bệnh nhân ung thư biểu mô dạ dày trên 70 tuổi được phẫu thuật cắt gần toàn bộ dạ dày, vét hạch tại Bệnh Viện $\mathrm{K}$ cơ sở Tân Triều từ tháng 06/2018 đến tháng $06 / 2021$.}


Tiêu chuẩn lựa chọn

- Tuổi $\geq 70$.

- Có kết quả giải phẫu bệnh sau mổ là ung thư biểu mô da dày.

- Được phẫu thuật triệt căn cắt gần toàn bộ dạ dày, vét hạch.

Tiêu chuẩn loại trừ

- Bệnh nhân mổ cấp cứu do các biến chứng của ung thư dạ dày.

- Bệnh nhân có thêm tổn thương ung thư tại vị trí khác.

- Bênh nhân có tiền sử phẫu thuật cắt đoạn dạ dày trước đó.

\section{Phương pháp nghiên cứu}

Nghiên cứu mô tả hồi cứu kết hợp tiến cứu

Chọn mẫu nghiên cứu: Sử dụng phương pháp chọn mẫu thuận tiện, lấy tất cả các bệnh nhân thỏa mãn tiêu chuẩn nghiên cứu.

Các bước tiến hành: Thu thập số liêu bênh nhân dựa trên bệnh án nghiên cứu. Thu thâp theo các biến tuổi, giới, bệnh lý nền, phân loại ASA, giai đoạn bệnh, thể mô bệnh học sau mổ, mức độ vét hạch. Đánh giá kết quả phẫu thuật bao gồm thời gian trung tiện, thời gian cho ăn, ghi nhận các biến chứng và tử vong sau mổ.

Phân tích số liệu: Dựa trên phần mềm SPSS 20.0.

\section{KẾT QUẢ NGHIÊN CỨU}

Bảng 1: Một số đặc điểm chung của bệnh nhân

\begin{tabular}{|c|c|c|}
\hline Đắc điếm & $\mathbf{n}$ & $(\%)$ \\
\hline Tuối trung bình & \multicolumn{2}{|c|}{$75,44 \pm 4,29$} \\
\hline $\begin{array}{ll}\text { Giới: } & \begin{array}{l}N a m \\
N \tilde{u}\end{array}\end{array}$ & $\begin{array}{l}73 \\
38\end{array}$ & $\begin{array}{l}65,8 \\
34,2\end{array}$ \\
\hline Bệnh lý nền & & \\
\hline
\end{tabular}

\begin{tabular}{|c|c|c|}
\hline Tăng huyết áp & 41 & 36,9 \\
Đái tháo đường & 15 & 13,5 \\
Các bệnh lý mạn tính khác & 12 & 10,8 \\
Có ít nhất một bệnh lý nền & 54 & 48,6 \\
\hline Phân loại ASA : II & 85 & 76,6 \\
III & 18 & 16,2 \\
IV & 8 & 7,2 \\
\hline Giai đoạn bệnh: I & 30 & 27,0 \\
II & 29 & 26,1 \\
III & 52 & 46,9 \\
\hline
\end{tabular}

Nhận xét: Tỷ lệ nam/nữ = 1,92;

$48,6 \%$ bệnh nhân có bệnh lý nền trong đó tăng huyết áp thường găp nhất với tỷ lê 36,9\%.

Đa phần bệnh nhân có ASA II $(76,6 \%)$, các bệnh nhân có ASA IV đều liên quan đến xuất huyết tiêu hóa nặng $(\mathrm{Hb}<80 \mathrm{~g} / \mathrm{l})$.

Về giai đoạn bệnh, nghiên cứu của chỉ tiến hành trên các bệnh nhân phẫu thuật triệt căn (giai đoạn I-III), giai đoạn III thường gặp nhất với $46,9 \%$.

Bảng 2: Kêt quả sớm sau mổ

Thời gian trung tiện(ngày $\mid 3,10 \pm 0,65(2-4)$

\begin{tabular}{|c|c|}
\hline Thời gian cho ăn (ngày) & $3,72 \pm 0,68(2-5)$ \\
\hline Thời gian nằm viện (ngày) & $\begin{array}{c}10,74 \pm 3,37 \\
(8-30)\end{array}$ \\
\hline Biến chứng sau mố & $13(11,7 \%)$ \\
\hline $\begin{array}{c}\text { Viêm phổi } \\
\text { Chảv máu sau mổ }\end{array}$ & $5(4,5 \%)$ \\
\hline $\begin{array}{l}\text { Cháy máu sau mố } \\
\text { Nhiễm trùng vết mổ }\end{array}$ & $3(2,7 \%)$ \\
\hline $\begin{array}{l}\text { Nhiem trung vet mo } \\
\text { Rò móm tá }\end{array}$ & $\begin{array}{l}2(1,8 \%) \\
1(0 \%)\end{array}$ \\
\hline Rò dưỡng chấp & $1(0,9 \%)$ \\
\hline Nhồi máu cơ tim & $1(0,9 \%)$ \\
\hline Tử vong & 0 \\
\hline
\end{tabular}
$11,7 \%$. Viêm phổi thường gặp nhất với 5 trường hợp (4,5\%). Không có trường hợp nào phải mổ lại và không có trường hợp tử vong sau mổ.

Bảng 3: Liên quan giữa biến chứng, thời gian nằm viện với bệnh lý nền và mức độ vét hạch

\begin{tabular}{|c|c|c|c|c|c|c|c|}
\hline \multicolumn{3}{|c|}{ Đặc điểm } & \multirow{3}{*}{$\begin{array}{c}\begin{array}{c}\text { Số bềnh } \\
\text { nhẩn }\end{array} \\
15 \\
96\end{array}$} & \multirow{3}{*}{$\begin{array}{c}\text { Biến chứng } \\
3(20,0 \%) \\
10(10,4 \%)\end{array}$} & \multirow{3}{*}{$\frac{\mathbf{p}}{>0,05}$} & \multirow{3}{*}{$\begin{array}{c}\begin{array}{c}\text { Số ngày nằm } \\
\text { viện }\end{array} \\
11,40 \pm 5,34 \\
10,64 \pm 2,98\end{array}$} & \multirow{3}{*}{$\frac{\mathbf{p}}{>0,05}$} \\
\hline \multirow{6}{*}{$\begin{array}{c}\text { Bênh } \\
\text { lý } \\
\text { nền }\end{array}$} & Đái tháo & Có & & & & & \\
\hline & & Không & & & & & \\
\hline & \multirow{2}{*}{$\begin{array}{c}\text { Tăng huyết } \\
\text { áp }\end{array}$} & Có & 41 & $5(12,2 \%)$ & \multirow{2}{*}{$>0,05$} & $11,44 \pm 4,67$ & \multirow{2}{*}{$>0,05$} \\
\hline & & Không & 70 & $8(11,4 \%)$ & & $10,33 \pm 2,25$ & \\
\hline & \multirow{2}{*}{ Chung } & Có & 54 & $7(13,0 \%)$ & \multirow{2}{*}{$>0,05$} & $10,96 \pm 4,19$ & \multirow{2}{*}{$>0,05$} \\
\hline & & Không & 57 & $6(10,5 \%)$ & & $10,53 \pm 2,37$ & \\
\hline \multirow{2}{*}{\multicolumn{2}{|c|}{$\begin{array}{l}\text { Mức độ } \\
\text { vét hạch }\end{array}$}} & D2 & 75 & $9(12,0 \%)$ & \multirow{3}{*}{$>0,05$} & $10,83 \pm 3,55$ & \multirow{3}{*}{$>0,05$} \\
\hline & & Dưới D2 & 36 & $4(11,1 \%)$ & & $10,56 \pm 3,01$ & \\
\hline \multicolumn{3}{|c|}{ Tống Số } & 111 & $13(11,7 \%)$ & & $10,74 \pm 3,37$ & \\
\hline
\end{tabular}

Nhân xét: Bệnh lý nền, vét hạch D2 không làm tăng nguy cơ biến chứng sau phâu thuật và thời gian nắm viện. Sự khác biệt không có ý nghĩa thống kê.

\section{BÀN LUÂN}

2. Một số đặc điểm chung của bệnh nhân. Mặc dù tỷ lệ mới mắc có xu hướng giảm trong những năm gần đây, ung thư dạ dày vẫn là một trong những ung thư phổ biến nhất và là nguyên nhân tử vong hàng đầu trong các loại 
ung thư. Độ tuổi trung bình theo nghiên cứu của chúng tôi là 75,44 $\pm 4,29$, tỷ lệ nam/nữ =1,92/1. Theo thống kê của GLOBOCAN 2020 với độ tuổi trên 70 , tỷ lệ nam/nữ xấp xỉ $1,73 / 1$, khu vực Đông Á tỷ lệ này $1,95 / 1$, Việt Nam là 1,2/1 [6].

$48,6 \%$ bệnh nhân có các bệnh lý nền đi kèm, trong đó thường gặp nhất là tăng huyết áp $(36,9 \%)$ và đái tháo đường $(13,5 \%)$, ngoài ra còn một số bệnh lý khác bao gồm suy tim, bệnh mạch vành, xơ gan còn bù, phổi tắc nghẽn mãn tính, bệnh thận mạn. 11 trường hợp $(9,9 \%)$ có ít nhất hai bệnh lý nền đi kèm. Đa phần các bệnh nhân có toàn trạng tương đối tốt, các bệnh lý nền được được điêu trị ổn định trước phẫu thuật. Đánh giá theo thang điểm $A S A$, chủ yếu các bệnh nhân có ASA II với tỷ lệ 76,6\% (do ung thư là bệnh lý toàn thân nên tất cá các bệnh nhân đều phân loại ASA II trở lên), các trường hợp ASA IV đều liên quan đến xuất huyết tiêu hóa nặng do ung thư được hồi sức truyền máu trước phẫu thuật.

Nghiên cứu cho thấy ung thư giai đoạn III thường gặp nhất. Qua tham khảo các nghiên cứu khác chúng tôi thấy rằng tại Việt Nam hiện nay ung thư dạ dày thường chẩn đoán ở giai đoạn tiến triển, như nghiên cứu của tác giả Đố Trường Sơn, 83,9\% bệnh nhân ung thư dạ dày chẩn đoán ở giai đoạn III-IV [1]. Trong khi đó tại Nhật Bản, nhờ các chương trình sàng lọc ung thư dạ dày, tỷ lệ ung thư dạ dày được chẩn đoán giai đoạn sớm ở mức cao và có xu hướng tăng lên trong những năm gần đây. Như nghiên cứu của tác giả Katai trong giai đoạn 2001-2007, tỷ lệ bệnh nhân ung thư dạ dày giai đoạn I là $54,7 \%$, giai đoạn II là $13,1 \%$, giai đoạn III là $12 \%$ và 14,2\% được chẩn đoán ở giai đoạn IV [2].

3. Kêt quả sớm của phẫu thuật. Thời gian nằm viện trung bình là $10,74 \pm 3,37$ ngày, đa phần các bệnh nhân ra viện trong khoảng 8-10 ngày với tỳ lệ $64,0 \%$, bệnh lý nền và vét hạch D2 không làm kéo dài thời gian nằm viện. Kết quả nghiên cứu của chúng tôi tương tự kết quả nghiên cứu của Đỗ Trường Sơn [1]. Tác giả này cũng chỉ ra không có sự khác biệt giữa thời gian nằm viện của đối tượng cao tuổi so với nhóm bệnh nhân trẻ. Thời gian trung tiện trung bình là $3,1 \pm 0,65$ ngày. Tất cả các bệnh nhân đều trung tiện trong vòng 2-4 ngày. Đa phần các bệnh nhân được cho ăn từ ngày thứ 3 hoặc thứ 4 sau mổ. Hiện nay nhiều phẩu thuật viên ủng hộ việc cho ăn sớm sau mổ, những lợi ích mà việc cho ăn sớm mang lại bao gồm kích thích nhu động ruột, đảm bảo dinh dưỡng cho bệnh nhân, hạn chế dịch truyền nhất là đối với các bệnh nhân có vấn đề tim mach.

Tỷ lệ biến chứng chung là $11,7 \%$. Trong đó viêm phổi thường gặp nhất với 5 trường hợp $(4,5 \%), 3$ trường hợp chảy máu sau mổ được điều trị nội khoa ổn định, 2 trường hợp nhiễm trùng vết mổ, 1 trường hợp rò mỏm tá được điều trị nội khoa ổn định ra viện sau 21 ngày. Không có trường hợp nào phải mổ lại và tứ vong sau mổ. Một số kết quả nghiên cứu cho thây tỷ lệ biến chứng sau mổ ở đối tượng cao tuổi dao động từ 10-35\% [1], [4], [5]. Tác giả Rausei cho thây tỷ lệ biến chứng sau mổ ở nhóm bệnh nhân trên 70 tuổi cao hơn so với nhóm dưới 70 tuổi [5]. Kết quả tương tự cũng được báo cáo theo nghiên cứu của $Y u$, tuổi $\geq 65(O R=1,72, p<0,05)$, có hai bệnh lý nền trở lên $(O R=2,76, p<0,05)$ là các yếu tố làm tăng nguy cơ biến chứng sau phẫu thuật [7]. Ngược lại, nghiên cứu của tác giả Katai lại cho thây tuổi cao và bệnh lý nền không làm tăng nguy cơ biến chứng [2]. Trong nghiên cứu của chúng tôi các bệnh nhân cao tuổi nhưng đa phần đều có thể trạng tương đối tốt, các trường hợp có bệnh lý nền đều được chỉ định khám chuyên khoa đầy đủ, điều chỉnh các rối loạn trong giới hạn cho phép tiến hành phẫu thuật, đồng thời được theo dõi tích cực hơn sau mồ, đó có thể là lý do giải thích tỷ lệ biến chứng không khác biệt so với nhóm bệnh nhân còn lại.

Tỷ lệ bệnh nhân được vét hạch D2 là 67,6\%, không có sự khác biệt về tỷ lệ biến chứng giữa nhóm bệnh nhân vét hạch $D 2$ so với vét hạch dưới D2 (12\% so với $11,1 \%, p>0,05)$. Thực tế việc quyết định mức độ vét hạch phụ thuộc vào tình trạng của từng bệnh nhân, chúng tôi thường ưu tiên vét hạch $D 2$ cho các bệnh nhân toàn trạng tốt, bệnh lý nền không có hoặc không nghiêm trọng. Nghiên cứu của tác giả Mikami trên đối tượng trên 70 tuổi cũng chỉ ra không có sự khác biệt về tỷ lệ biến chứng và tử vong sau mổ đối với nhóm bệnh nhân được vét hạch chuẩn so với vét hạch giới hạn $(15,3 \%$ so với $18,6 \%, p>0,05)$ [4]. Trong khi đó nhiêu nghiên cứu khác chỉ ra rằng vét hạch $\mathrm{D} 2$ làm tăng tỷ lệ biến chứng sau mổ [3]. Việc có chọn lọc bệnh nhân để chỉ định mức độ vét hạch của mỗi tác giả là khác nhau có thể dẫn đến sự khác biệt của các kết quả nghiên cứu. Do đó, việc quyết định lựa chọn mức độ phẫu thuật cân được cá thể hóa theo tình trạng người bệnh và kinh nghiệm của phẫu thuật viên.

\section{KẾT LUẬN}

Phẫu thuật triệt căn cắt gần toàn bộ dạ dày ở người trên 70 tuổi có thể tiến hành an toàn, tuy 
nhiên cần phải đánh giá kĩ các bệnh lý nền để kiểm soát trong ngưỡng ổn định trước khi tiến hành phẫu thuật. Việc lựa chọn vét hạch D2 hay dưới D2 cần cân nhắc dựa trên đặc điểm của từng người bệnh.

\section{TÀI LIÊU THAM KHẢO}

1. Đố Trường Sơn (2014). Điều trị phẫu thuâtt ung thư dạ dày ở người cao tuổi. $Y$ học Việt Nam. 418(2), 135-138.

2. Katai H., Ishikawa T., Akazawa $K_{\text {., }}$ et al (2018). Five-year survival analysis of surgically resected gastric cancer cases in Japan: a retrospective analysis of more than 100,000 patients from the nationwide registry of the Japanese Gastric Cancer Association (2001-2007). Gastric cancer. 21(1), 144-154.

3. Memon M., Subramanya M., Khan S., et al (2011). Meta-analysis of D1 versus D2 gastrectomy for gastric adenocarcinoma. Annals of surgery. 253(5), 900-911.
4. Mikami K., Hirano K., Futami K., et al (2018). Gastrectomy with limited surgery for elderly patients with gastric cancer. Asian journal of surgery. 41(1), 65-72.

5. Rausei S., Ruspi L., Rosa F., et al (2016). Extended lymphadenectomy in elderly and/or highly co-morbid gastric cancer patients: A retrospective multicenter study. European journal of surgical oncology. 42(12), 1881-1889.

6. Sung H., Ferlay J., Siegel R., et al (2021). Global cancer statistics 2020: GLOBOCAN estimates of incidence and mortality worldwide for 36 cancers in 185 countries. CA: a cancer journal for clinicians.

7. Yu J., Hu J., Huang C., et al (2013). The impact of age and comorbidity on postoperative complications in patients with advanced gastric cancer after laparoscopic D2 gastrectomy: Results from the Chinese laparoscropic gastrointestinal surgery study group. European Journal of Surgical Oncology. 39 (10), 1144-1149.

\section{TÌM HIỂU BIẾN THIÊN NHİP TIM Ở BỆNH NHÂN ĐÁI THÁO ĐƯờNG TYP 2 CÓ ĐƯờNG HUYẾT KHÔNG ỔN ĐİNH}

\section{TÓM TẮT}

Biến thiên nhịp timphản ánh tác động của thần kinh tự chủ lên tim và có giá trị tiên lượng khả năng xuất hiện rối loạn nhịp timnguy hiểm và tỷ lệ tử vong. Người bệnh Đái tháo đường có tỷ lệ cao biến chứng thần kinh tự chủ làm giảm chất lượng cuộc sống và tăng nguy cơ tử vong tim mạch. Mục tiêu của nghiên cứu này là: Khảo sát một số chỉ số biến thiên nhịp tim ở người bênh Đái tháo đường type 2 có đường huyết không ổn đinh bằng Holter điện tâm đồ 24 h và tìm hiểu mối tương quan giữa một số chỉ số biến thiên nhịp tim với nồng độ đường huyết ở đối tượng nghiên cứu. Đối tượng và phương pháp nghiên cứu: Mô tả cắt ngang 50 người bênh Đái tháo đường có đường huyết không ổn định được theo dõi Holter điện tâm đồ 24 giờ và đường máu mao mach 5 lần trong ngày. Kết quả nghiên cứu: Các chỉ sổ biến thiên nhịp tim như độ lệch chuẩn của các nhát bóp bình thường trên toàn bộ Hoter điện tim 24 giờ (SDNN), trung bình của độ lệch chuẩn tất cả các khoảng RR bình thường của tẩt cả các đoạn 5 phút trên toàn bộ Holter điện tim 24 giờ (ASDNN), độ lệch chuẩn của các khoảng RR bình thường trong mối 5 phút của toàn bộ Holter điện tim 24 giờ (SDANN),

\footnotetext{
${ }^{1}$ Bệnh viện Đa khoa tỉnh Hà Nam

2Viện Tim mạch Việt Nam - Bệnh viện Bạch Mai

Chịu trách nhiệm chính: Phạm Trần Linh

Email: ptlinhmd@gmail.com

Ngày nhận bài: 9.7.2021

Ngày phản biện khoa học: 3.9.2021

Ngày duyệt bài: 10.9.2021
}

\section{Trần Thị Tâm ${ }^{1}$, Phạm Trần Linh ${ }^{2}$}

trung bình của căn bậc hai tổng các bình phương đoạn RR (RMSSD) ở người bệnh Đái tháo đường typ 2 có đường huyêtt không ổn định đều thấp hơn so với người khỏe mạnh. Nhóm hạ đường huyết có các chỉ số biến thiên nhịp tim theo thời gian thấp hơn nhóm đường huyết cao. SDNN, ASDNN, SDANN tương quan thuận với $\mathrm{HbA} 1 \mathrm{c}$ ở nhóm đường huyết cao và tương quan nghịch với HbA1c ở nhóm ha đường huyết. Các chỉ số biến thiên nhip tim theo thời gian tương quan tương quan nghịch hoặc không có mối tương quan với nồng độ đường huyết các thời điểm kiểm tra. Thời khoảng QT hiệu chỉnh tối đa (QTc max) ở nhóm hạ đường huyết cao hơn nhóm đường huyết cao và có tương quan nghịch mức độ vừa với nồng độ đường huyết $6 \mathrm{~h}$ và $11 \mathrm{~h}$ trước ăn ở nhóm hạ đường huyết. Các rối loạn nhịp tim không tương quan với nồng độ đường huyểt. Kểt luận: Các chỉ số biến thiên nhịp tim theo thời gian ở bệnh nhân Đái tháo đường typ 2 thấp hơn so với người khỏe mạnh và có tương quan vừa với HbA1c, tương quan yếu với nồng độ đường huyêt.

Tì̛ khóa: Biến thiên nhịp tim, Đái tháo đường, Đường huyết không ổn định.

\section{SUMMARY \\ HEART RATE VARIABILITY IN DIABETES MELLITUS TYP 2 PATIENTS WITH UNCONTROL BLOOD GLUCOSE LEVELS}

Heart rate variability (HRV) reflects cardiac autonomic nervous function and predicts risk of serious arrhythmia and mortality. Diabetes mellitus patients have high rate cardiac autonomic nervous dysfunction and arterial diseases, so they are reduced quality of life and significantly increased cardiovascular 